\title{
Quality Assessment of Some Brands of Levofloxacin 500mg Tablets Commercially Available in Gwagwalada, Abuja
}

Victoria Deborah Onalo $^{1 *}$, Danraka Abubakar ${ }^{2}$, Stephen Monday Chibuyojo ${ }^{1}$

\author{
${ }^{1}$ Department of Pharmacy, University of Abuja Teaching Hospital, Gwagwalada Abuja, Nigeria \\ ${ }^{2}$ Department of Pharmacy, National Hospital Abuja, Nigeria
}

DOI: $10.36347 /$ sajp.2021.v10i03.002

| Received: 19.02.2021 | Accepted: 02.03.2021 | Published: 04.03.2021

*Corresponding author: Victoria Deborah Onalo

Abstract

Original Research Article

Background: Levofloxacin, a third generation fluoroquinolone and the L-isomer of the racemate ofloxacin with improved antimicrobial activities. It is mostly prescribed and utilized in the health sectors within Abuja, as a result high influx of different and cheaper brands of both genuine and substandard levofloxacin tablets in Gwagwalada metropolis. So, quality evaluation of some of these brands of levofloxacin tablets is of prior importance. Objective: This study is aimed to determine the physicochemical properties and the quantitative assay of five different brands of levofloxacin 500mg tablets within Gwagwalada Abuja. Methods: The physicochemical tests were evaluated by checking the weight uniformity, friability, disintegration, dissolution; according to BP established methods for five(5) different brands of levofloxacin 500mg tablets. The assay for determination of active ingredientfor these brands were carried out using the UV/visible spectrophotometry. Results: All the brands tested complied with official British Pharmacopoeia specifications. The physicochemical test showed Uniformity of weight $(-0.13-0.22 \%)$, Friability $(0.007-0.075 \%)$, Disintegration $(2.05-15.34$ minutes $)$. The percentage release for the dissolution test showed that more than $80 \%$ of the drugs were released within 10minutes. However for the contents uniformity, two of the brands (LEVO-1 and LEVO-3 have percentage content of 84.5-85.5\%) failed to meet the official stipulated monograph of 90 $-110 \%$. While the remaining three (LEVO-2, LEVO-4 and LEVO-5) have percentage content value ranging from 92 to $103.7 \%$, and therefore can be interchangeable. Conclusion: Pharmaceutical equivalence is obtainable for the brands test in the physicochemical test. Quantitative assay showed that three (3) of the tested brands can be interchangeable while two brands can be said to be substandard. So, it is important that regulatory agencies to embark on postmarketing quality analysis levofloxacin $500 \mathrm{mg}$ tablets of both locally manufactured drugs and drugs imported on periodic bases

Keywords: Levofloxacin Tablet, quality assessment, Physicochemical Tests, Assay.

Copyright (C) 2021 The Author(s): This is an open-access article distributed under the terms of the Creative Commons Attribution 4.0 International License (CC BY-NC 4.0) which permits unrestricted use, distribution, and reproduction in any medium for non-commercial use provided the original author and source are credited.

\section{INTRODUCTION}

Fluoroquinolone a broadspectrum antibiotic that is widely used for bacterial infections, among this class is Levofloxacin [1]. Antibiotics are the most frequently prescribed drugs among hospitalized patients and there is reported concern about the continuous indiscrimate excessive use of antimicrobial agents. This excessive use and irrational prescribing of the antibiotic promote the emergence of antibiotic resistant organisms and thereby leading to treatment failure [2]. The rates of pathogens resistant to currently available antibiotics is on on the heighess level. The developing world, being an integral part of the wide range village is not insulated from this trend [3]. Poor quality medicines are products whose composition and ingredients do not meet official standards in terms of strength, quality, purity, packaging and labelling. The products may be ineffective and dangerous to the patient [4]. Poor quality medicines have major consequences on health of populations and the function of the health system. Poor quality drugs can affect the treatment of patients, increase antimicrobial drug resistance and decrease trust in health providers. The presence of a medicine on the World Health Organisation Essential Medicine List is however not an assurance of the pharmaceutical quality of the medicine. It is therefore the responsibility of the relevant national and regional medicines regulatory authorities to ensure that medicines within their jurisdiction are of the right quality and stability through the application of integrated pharmacovigilance and drug surveillance systems [5]. The quality of medicines can be compromised during manufacture, distribution 
Victoria Deborah Onalo et al., Sch Acad J Pharm, Mar, 2021; 10(3): 43-48

within country and storage at elevated temperatures and humidity conditions [6]. There is the need for proper quality assurance and post market surveillance of medicine produced within the country. This can easily be carried out by regulatory and allied authorities to ensure the quality of the drug produced.

Quinolone comprise an interesting group of antibacterial whose action is based on their antiDNAgyrase and topoisomerase intracellular activities. Their antibacterial activity is greatly increased by addition of 6-fluoro and 7-piperazinyl groups to the molecule giving rise to the novel 6-fluoroquinolones commonly referred to as the fluoroquinolone antibacterial agents. They are the second generation members of quinolones and are greatly effective against both Gram-negative and Gram-positive bacteria that are resistant to other antibacterial [7].

Levofloxacin which is the focus of this study is a third generation fluoroquinolone and it is the L-isomer of the racemate ofloxacin with improved antimicrobial activities [8]. Levofloxacin is a 6-fluoroquinolone antibacterial agent and it acts as a broad-spectrum antibiotic against gram-positive and gram-negative aerobes. It was patented in 1987 and approved by the United States Food and Drug Administration in 1996 for use in the United States and marketed by SanofiAventis under the name Tavanic [9]. Levofloxacin functions by diffusing through the bacterial cellwall acts by inhibiting DNA gyrase, a type II topoisomerase and IV enzyme required for DNA replication, RNA transcription and repair of bacteria DNA. Inhibition of DNA gyrase activity will lead to blockage of bacterial cell growth. Levofloxacin is a newer member among the fluoroquinolones. It is the L-isomer of ofloxacin which is existing commercially as the hemihydrates. Levofloxacin is chemically known as;

Chemical name: (-)-(s)-9-fluoro-2,3-dihydro-3-methyl10-(4-methyl-1-piperazinyl)-7-

Oxo-7H-pyridol [1,2,3-de]-1,4benzoxazine-6carboxylic acid, Hemihydrates.

Molecular formula: $\mathrm{C}_{18} \mathrm{H}_{20} \mathrm{FN}_{3} \mathrm{O}_{4} \cdot \frac{1}{2} \mathrm{H}_{2} \mathrm{O}{ }^{10}$

Molecular weight: $361.368 \mathrm{~g} / \mathrm{mol}$.

Appearance; light yellowish-white to yellow-white crystalline powder. It is freely soluble in acidic aqueous solutions but relatively insoluble in water [11].<smiles>C[C@H]1COc2c(N3CCN(C)CC3)c(F)cc3c(=O)c(C(=O)O)cn1c23</smiles>

Fig-1: Chemical structure of levofloxacin
Levofloxacin tablet with influx of newer different brands and emergence of cheaper products in the drug market may lead to difficulty in making choice and can pose a public health risk. The tendency of patients to have preference for cheaper brands is inevitable. This is not unconnected with the low socioeconomic status of the populace amidst high cost of living in Gwagwalada. Generally, the effectiveness of pharmaceutical dosage forms depends on their formulation properties and manufacturing method. The likelihood is that the quantity of various dosage forms may vary depending on the manufacturer [12]. Hence it is important to validate the quality of some of the available levofloxacin tablets in Gwagwalada metropolis. The physicochemical properties of the tablets Levofloxacin to be considered in this study include; uniformity of weight, tablet friability, disintegration time test, dissolution and determination of content uniformity.

The objective of this study was to evaluate the physicochemical properties of five different brands of Levofloxacin $500 \mathrm{mg}$ tablet that is commercially available in Gwagwalada metropolis.

\section{MATERIALS AND METHODS STUDY SETTING}

The study was carried out in Gwagwalada town located in Gwagwalada Area Council of Federal Capital Territory Nigeria. Gwagwalada town is one of the largest satellite towns and the third largest urban centre in the Federal Capital Territory. It is one of the most densely populated towns in the Federal Capital Territory. Gwagwalada Area Council lies between latitude $08^{0} 55 \mathrm{~N}$ 'and $09^{0} \quad 00 \mathrm{~N}$ 'and longitude $07^{0}$ $00 \mathrm{E}^{\prime}$ and $07^{0} 05 \mathrm{E}^{\prime}$ [13]. It is bordered in the South by Kwali Area Council, in the North by Niger state, Kuje Area Council in the East and Abuja Municipal Area Council in the North-East. It has a tropical climate with the temperature ranging from $30^{\circ}-37^{\circ} \mathrm{C}$, with the highest recorded in the month of March. It is estimated to have a population of 402,000 , with population density of $385.4 / \mathrm{km}^{2}$ [14].

\section{MATERIALS \& REAGENTS}

The materials that was used for this research work includes; A Chinese Pharmacopeia Reference Levofloxacin 100mg which was purchased from Adel Crystals and Five (5) different brands of levofloxacin tablets with label of $500 \mathrm{mg}$. The reagent that was used is HCL $36.46 \% \mathrm{w} / \mathrm{v}$ (822A994315 Art.8215), and Distilled water. The following equipment were used in the research work: Digital Analytical balance (ApexFB51634 made in USA), Digital Friability Tester (model-902/903 made in Indian), Disintegration test apparatus (Erweka tablet Disintegration tester ZT 3 Nr:41728 made in Western Germany), Erweka tablet Dissolution app DT Nr: 43560, made in Western Germany, UV Spectophotometer (model UV-1800, 
Victoria Deborah Onalo et al., Sch Acad J Pharm, Mar, 2021; 10(3): 43-48

Shmadzu, Germany) and Volumetric flask, Pipette, Filter paper, Ceramic mortar and pestle.

\section{Reference and Test Drugs}

Reference Levofloxacin powder (Chinese Pharmacopoeia Standard) was procured through ADELS CRYSAL LAKE NIG LTD in Lagos and five(5) different brands of Levofloxacin tablets labelled to contain $500 \mathrm{mg}$ of active ingredient from different manufacturer which were randomly purchased using systematic random sampling technique, from registered Pharmaceutical stores in Gwagwalada.

\section{Physicochemical test}

The following physicochemical properties were determined: Tablet Weight Uniformity, Tablet Friability, Disintegration Time Test, Dissolution test and Determination of Content Uniformity.

\section{Uniformity of Weight}

Twenty (20) tablets were randomly selected from each brand and were weighed individually using a digital analytical balance. The weights of the tablet were recorded and the mean, standard deviation and percentage deviation were calculated. Not more than two of the individual weight should deviate from the average weight by more than the percentage deviation: $80 \mathrm{mg}$ or less for $\pm 10 \%$ and more than $80 \mathrm{mg}$ or less than $250 \mathrm{mg}$ for $\pm 7.5 \%, \pm 5 \% 250 \mathrm{mg}$ and more [15].

\section{Friability test}

This test helps to measure the resistance of the tablet to abrasion. Tablets are subjected to a standardized level of agitation for a given time and friability is expressed as weight loss.

Twenty (20) tablets of each brand were weighed using the electronic analytical balance. The tablets were placed in the drum of Digital Friability tester which is already set to operate at a speed of 25 revolutions per minute for four minutes in a total of 100 revolutions. The tablets were dropping through a distance of six inches with each revolution. After 100 revolutions the tablets were reweighed and the percentage loss in tablet weight is determined. The test is done once if the tablets are obviously cracked or broken tablets are present after tumbling, the sample then is reported as failed the test. Generally, a maximum loss of weight not greater than $1 \%$ is considered acceptable for most products. ${ }^{15}$

\section{Disintegration test}

Disintegration test was provided to determine whether tablets disintegrate within the prescribed time when placed in a liquid medium under certain experimental condition. $900 \mathrm{ml}$ of the $0.1 \mathrm{~N}$ HCL were measured and poured into $1000 \mathrm{ml}$ capacity beaker, the content and the beaker were placed in the disintegration machine. The temperature of the apparatus was maintained at $37^{\circ} \mathrm{C} \pm 0.5^{\circ} \mathrm{C}$ with the aid of a thermostated heater. Six tablets were randomly selected from each brand and were placed in the basket rack assembly, hung on a metal holder and lowered into the beaker containing the disintegration medium. The machine was turned on and the basket oscillated up and down until the tablets were disintegrated [15]. The time taken for each tablet to disintegrate was recorded. The process was repeated for all the brands.

\section{Determination of Content of Uniformity}

The determination of content uniformity, was done using the UV-Visible Spectrophotometer. This was done using the developed and validation method [10].

\section{Preparation of standard stock solution}

$50 \mathrm{mg}$ of pure levofloxacin powder was weighed and dissolved in $100 \mathrm{ml}$ of $0.1 \mathrm{NHCl}$. Then $10 \mathrm{ml}$ of this solution was further diluted to $100 \mathrm{ml}$ with $0.1 \mathrm{NHCl}$ to obtain $50 \mu / \mathrm{ml}$ Levofloxacin hemihydrates solution known as L0. A serial dilution from L0 was made using $0.1 \mathrm{NHCl}$ starting from 0.05 to $0.5 \mathrm{ml}$ which were taken and diluted to $10 \mathrm{ml}$ to obtain different concentrations within the range of $0.25-2.5 \mu / \mathrm{ml}$. These were passed through the UV-Visible Spectrophotometer at the wavelength of $290 \mathrm{~nm}$. A plot of concentration against absorbance was made and it's coefficient of determination $\left(\mathrm{r}^{2}\right)$ was calculated.

\section{Dissolution Test}

The dissolution rate of tablets was determined using the USP dissolution test apparatus. Dissolution test was set up using a freshly prepared $900 \mathrm{ml}$ of $0.1 \mathrm{NHCL}$ medium at temperature regulated at $37 \pm 0.5^{\circ}$ c. The agitator switch was turned on and set to the speed 100 revolution per minute. This was done at intervals of $5,10,15,20,25,30,35,40$, and 45minutes, a tablet from each brand was placed in a basket and then allowed to be dropped in the medium and rotate. A $5 \mathrm{ml}$ sample of fluid was withdrawn at $5 \mathrm{~min}$ intervals using $5 \mathrm{ml}$ syringe and needle. The volume withdrawn was replaced equal volume of fresh $0.1 \mathrm{NHCL}$ to maintain constant volume in the dissolution vessel. The sample withdrawn was filtered using $0.45 \mu \mathrm{m}$ filter paper and transferred into a sample bottle before subjecting it to UV Spectrophotometer reading at 290nm wavelength [16].

\section{Preparation of sample solution}

Ten tablets of the same brand were weighed and powdered using mortar and pestle to pulverize to fine powder. An accurate weighed tablet powder, equivalent to $50 \mathrm{mg}$ levofloxacin hemihydrates from the total weigh of the tablets pulverized, which was transferred into $100 \mathrm{ml}$ volumetric flask. $50 \mathrm{ml}$ of $0.1 \mathrm{NHCl}$ was added, and shaken for fifteen (15) minutes and diluted to $100 \mathrm{ml}$ mark with the same solvent. It was then filtered to obtain sample stock. $10 \mathrm{ml}$ of the filtrate was measured and further diluted to $100 \mathrm{ml}$ with the $0.1 \mathrm{NHCl}$. Then aliquot volume of 0.05 
Victoria Deborah Onalo et al., Sch Acad J Pharm, Mar, 2021; 10(3): 43-48

to $0.5 \mathrm{ml}$ were taken and diluted to $10 \mathrm{ml}$ each to get a concentration of 0.25 to $2.5 \mu / / \mathrm{ml}$. The absorbance of the sample solution were determined at $290 \mathrm{~nm}$ using the $0.1 \mathrm{NHCl}$ as the blank. The percentage drug content was calculated for each batch. It is stated that Levofloxacin tablet must have $90-110 \%$ of the label claim for it to pass the content of active ingredient [17].

\section{RESULTS}

The physicochemical properties test carried out for the tested brands of levofloxacin 500mg tablets includes; determination of uniformity of weight, friability, disintegration time, content uniformity and dissolution test. The Uniformity of Weight test for the five (5) different brands levofloxacin 500mg tablets showed that all the brands were within the official standard. British Pharmacopoeia stipulates for tablet $250 \mathrm{mg}$ or more, percentage deviation should not be more $\pm 5 \% .{ }^{18}$ The percentage deviation value is ranging from $-0.13-0.22 \%$.

The Friability test for the tested brands of levofloxacin $500 \mathrm{mg}$ tablets were within the official standard percentage loss of not more than $1 \%$, the value of the percentage loss ranging from $0.007-0.075 \%$.

The Disintegration test result for the tested brands of levofloxacin 500mg tablets showed that all the brands passed the disintegration time test. The official stipulated disintegration time test for the film coated tablet should not be more than $30 \mathrm{~min}$. The value for disintegration test for the brands is from 2.05-15.34 $\min$.

The drug content result showed that, three (3) of the tested brands of the levofloxacin 500mg tablets were within the official stipulation of $90-110 \%$. The value of the percentage content is from 92-103.6\%. LEVO-1 and LEVO-3 failed the test with value of 84.9$85.5 \%$.

The Dissolution test result showed that all the tested brands of the levofloxacin 500mg tablets pass the dissolution test. The percentage release showed that more than $80 \%$ of the drugs were release within $10 \mathrm{~min}$.

Table-1: Physicochemical parameter of five different brands of levofloxacin tablets

\begin{tabular}{|l|l|l|l|l|l|l|}
\hline $\begin{array}{l}\text { Product } \\
\text { code }\end{array}$ & $\begin{array}{l}\text { Mean } \\
\text { weight } \mathbf{\pm S D}\end{array}$ & $\begin{array}{l}\text { Percentage } \\
\text { Deviation }\end{array}$ & \%Friability & $\begin{array}{l}\text { Mean } \\
\text { Disintegration } \mathbf{\pm S D}\end{array}$ & $\begin{array}{l}\text { Percentage } \\
\text { Content }(\mathbf{9 0}- \\
\mathbf{1 1 0 \%}\end{array}$ & $\begin{array}{l}\text { Drug } \\
\text { Content } \\
(\mathbf{m g})\end{array}$ \\
\hline LEVO-1 & $718.8 \pm 3.89$ & 0.02 & 0.056 & $6.23 \pm 0.86$ & 85.5 & 427.5 \\
\hline LEVO-2 & $589.3 \pm 3.73$ & 0.22 & 0.042 & $7.95 \pm 2.33$ & 103.6 & 518.0 \\
\hline LEVO-3 & $689.7 \pm 4.78$ & -0.13 & 0.007 & $8.01 \pm 0.99$ & 84.9 & 424.5 \\
\hline LEVO-4 & $594.6 \pm 4.70$ & 0.04 & 0.076 & $2.05 \pm 0.33$ & 100.7 & 503.5 \\
\hline LEVO-5 & $696.1 \pm 3.91$ & 0.03 & 0.007 & $15.34 \pm 2.23$ & 92.0 & 460.0 \\
\hline
\end{tabular}

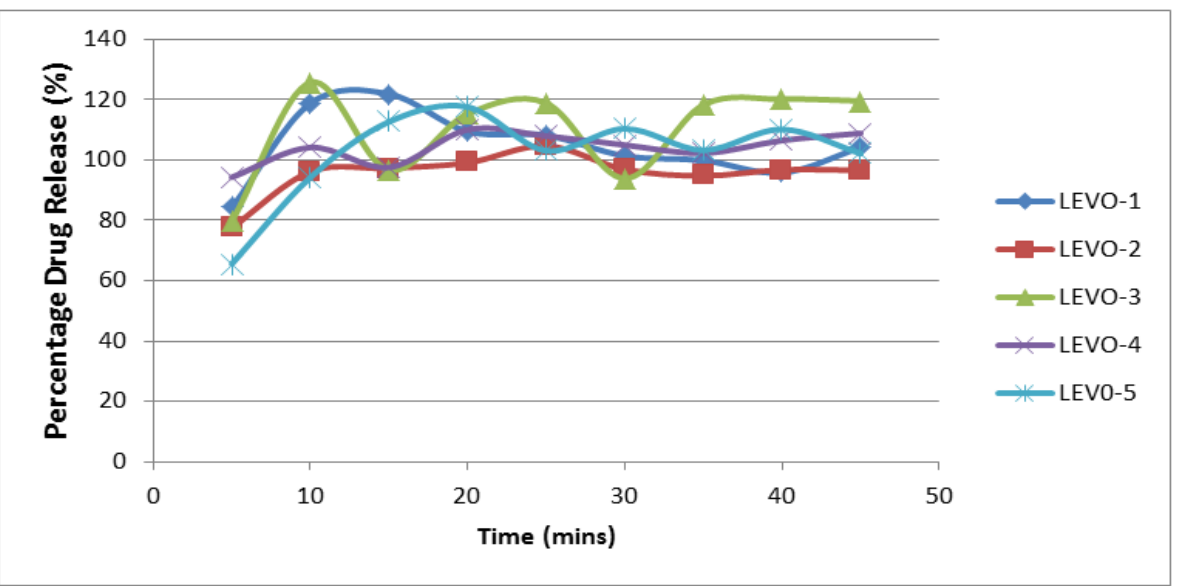

Fig-2: Dissolution profile for tested brands of levofloxacin $500 \mathrm{mg}$

\section{DISCUSSION}

The proliferation of small scale pharmaceutical industries has led to the availability of drugs of different qualities worldwide, Nigeria being inclusive. The dense population of Gwagwalada community with low socioeconomic status create a conducive environment for drugs of any kind to be marketed for patient use. So it is necessary to evaluate the drugs entering Gwagwalada most especially Levofloxacin, a
Fluoroquinolone most utilized. Five different brands of levofloxacin were purchased from the pharmacy outlets in Gwagwalada town. Eighty percent of the levofloxacin brands tested were manufactured in Indian with $20 \%$ indigenous. This show influx of Levofloxacin tablets from Indian to Africa.

Uniformity of weight can be used as a pointer for good manufacturing practices, although the 
Victoria Deborah Onalo et al., Sch Acad J Pharm, Mar, 2021; 10(3): 43-48

formulation and the manufacturing process can influence the weight of different brands of the same drug. For drugs of average weight $250 \mathrm{mg}$ or more, a percentage deviation of $\pm 5 \%$ is permitted [18]. The levofloxacin $500 \mathrm{mg}$ tablet brand that was tested had deviation ranging from -0.13 to $0.22 \%$, suggesting that all the twenty tablets used from each brand did not exceed the limit and it is considered therefore to have passed the weight uniformity test. It compares well with the study reported in India that the six different brands of film coated tablets of levofloxacin 500mg passed the weight variation test as the percentage of weight variation was within the USP limits of $\pm 5 \%$ of average weight [20].

The friability test is a very important test, because it helps to evaluate the ability of a tablet resistance to abrasion, the tablet friability permitted is less than 1\% [18]. A highly friable tablet can easily experience chipping, cracking or lamination during transportation, handling or accidental falls. From the result obtained, the entire levofloxacin $500 \mathrm{mg}$ tablet passed the test. It also conforms to the study conducted in Lagos Nigeria that showed ten different brands of levofloxacin 500mg tablet which passed the friability test [3]. The levofloxacin $500 \mathrm{mg}$ tablet brand tested ranging from 2.05 to 15.34 minutes for film coated tablets passed the disintegration test. The conformation of the tested tablets to the specified official monograph shows that the tablets can easily disintegrate within the normal stipulated time in the system and so, therapeutic efficacy can easily be achieved. LEVO-4 had the least time of disintegration which agrees with study that rapid disintegration is also attributable to the nature and concentration of the disintegrant used in the formulation as well as the manufacturing process employed [19].

The content of uniformity test was carried out using UV-Vis-Spectrophotometer. Levofloxacin should have percentage content between $90-110 \%$ [17]. This test revealed that all the five brands tested contained levofloxacin as their active ingredient. LEVO-2, LEVO-4 and LEVO-5 passed the test with percentage content of $103.6 \%, 100.7 \%$ and $92.0 \%$. But LEVO-1 and LEVO-3 did not meet the criteria with their percentage content being $85.5 \%$ and $84.9 \%$ respectively. This is in contrast to a study reported in India that all the six brands of levofloxacin 500mg tablets tested were within the official stipulated official monograph [20]. It compares well with the study conducted in Lagos, Nigeria, that revealed two of the 10 tested brands failing the content uniformity test [3]. LEVO-2 LEVO-4 and LEVO-5 shows that the quality of these drugs is excellent and can elicit a therapeutic effect without delay. The LEVO-1 and LEVO-3 did not meet the stipulated criteria; it is an indicative of substandard product which cannot produce the required therapeutic dose.
Not less than $80 \%$ of the labelled amount of levofloxacin dissolved in 30 minutes. ${ }^{18}$ The obtained dissolution profile (Fig-2) revealed that at 30mins, all levofloxacin brands attained more than $80 \%$ release. It is similar to the findings of the study conducted in Lagos that all the tested levofloxacin 500mg tablet brands attained more than $80 \%$ release except one brand which did not meet the criteria [3]. This shows that the entire levofloxacin brand complied with the USP specification. A drug product is considered to be very rapidly released if $\geq 85 \%$ of the drug is dissolved in 15 minutes [21]. There were faster rate of dissolution for LEVO-1 and LEVO-4 having above $80 \%$ within 5 minutes among all the brands. This indicates that these brands were released very rapidly which can be attributed to the manufacturing process and composition of excipient used. The test showed that the tested brands of levofloxacin have the capacity to be available in the system within the stipulated time.

\section{CONCLUSION}

The results obtained from the physicochemical properties shows that all the brands comply with the official standard, thereby allowing Pharmaceutical equivalence. The quantitative assay test showed that LEVO-2, LEVO-4and LEVO-5 met the official range stipulated for the percentage content uniformity except for LEVO-1 and LEVO-3 which did not meet the official range, probably due to poor quality granule used. This shows that the tested brands that meet the criteria are said to be chemically and pharmaceutically equivalent. Therefore generic substitution is permitted for these brands. The failed brands LEVO-1 and LEVO-3 shows that at every production of five different brands there can be two that are substandard. This is a high percentage which can lead to treatment failure, longer stay in the hospital, economic and human resource wastage in the country, damage to the patient and even death.

\section{REFERENCES}

1. Henry AO, Ikhuoria MA. Analytical Profile of the Fluoroquinolone antibacterials. African Journal of Biotechnology. 2008; 7(6):670-680.

2. Krivoy N, Abed El-Ahal W, Bar-Lavie Y, Haddad S. Antibiotic prescription and cost patterns in a general intensive care unit. Pharmacy Practice (Internet). 2007 Jun;5(2):67-73.

3. Chukwuemeka PA, Samson OO. Physicochemical and Bioequivalence studies of Some Brands Levofloxacin tablet registered in Nigeria. British Journal of Pharmaceutical Research. 2014; 4(16).

4. United State Pharmaceutical. What is drug quality and why is it important? 2010. http://www.usp.org/worldwide/dqi/drugQuality.ht $\mathrm{ml}$

5. Conway J, Bero L, Ondari C, Wasan KM. Review of the quality of pediatric medications in developing countries. Journal of pharmaceutical sciences. 2013 May 1;102(5):1419-33. 
Victoria Deborah Onalo et al., Sch Acad J Pharm, Mar, 2021; 10(3): 43-48

6. Hogerzeil HV, Battersby A, Srdanovic V, Hansen LV, Boye O, Lindgren B, Everitt G, Stjernstrom NE. WHO/UNICEF study on the stability of drugs during international transport. Geneva: World Health Organization; WHO/DAP/91.1; 1991.

7. Gomes GC, Salgado HRN. Validation of UV Spectrophotometric method for determination of Levofloxacin in Pharmaceutical Dosage Form. Acta Farm Bonaerense. 2005; 24(3): 406-408.

8. Tanaka K, Iwamoto M, Maesaki S, Koga H., Kohnos S, Sakito. Laboratory and Clinical studies on Lemofloxacin Jpn Antibiotic. 1992;45(5):54856.

9. Schaumann R, Rodloff AC. Activity of quinolones against obligately anaerobic bacteria. Anti-infective Agents in medicinal chemistry. 2007;6(1):49-56.

10. Desai VN, Afieroho OE, Dagunduro BO, Okonkwo TJ, Ndu CC. A Simple UV Spectrophotometric method for the determination of Levofloxacin in dosage formulation. Tropical Journal of Pharmaceutical Research. 2011;10(1):75-79.

11. Singh P, Chaudhari VK, Verma PK, Singh AK, Yadav VK. Development and validation of UV Visible Spectrometric method for the determination of Levofloxacin in bulk and tablet formulation. International Journal of Research and Development in Pharmacy and Life Sciences, 2015; 4(1):13751378.

12. Nayak AK. Comparative invitro dissolution assessment of some commercially available paracetamol tablets. International Journal of Pharmaceutical Review and research. 2010; 2:2930.
13. Balogun A. The position and influence of the Gwaga lada Area Council University of Lagos Press, 2001; pp, 35-42.

14. National Population Commission of Nigeria, 2017.

15. British Pharmacopoeia. British Pharmacopoeia Commission $8^{\text {th }}$ ed. Great Britain Stationery Office London. Appendix XII C- XVII G, 2014.

16. United State Pharmacopoeia, 37-National Formulary 32, United States Pharmacopoeia convention, Rockville, MD, USA. 2014.

17. United State Pharmacopoeia, 40-National Formulary 35, United States Pharmacopoeia convention, Rockville, MD, USA. 2017.

18. British Pharmacopoeia, Vol. 1. The Pharmaceutical Press, HER Majesty stationery office. London. 2012; 1-3.

19. Odeniyi MA, Adegoke-Remilekun OA, Adereti B, Odeku OA, Itiola, OA. Tropical journal of Pharmaceutical Reseach. 2003; 2(1):161-167.

20. Poornachandra TM, Prudviral A, Kalembe R, Avijit R, Lakshini S. Comparative In-Vitro Bioavailability Studies on Different Brands of Levofloxacin Tablets. ACTA Scientific Pharmaceutical Sciences. 2019; 3(1):50-54.

21. Food and Drug Administration, Center for Drug Evaluation and Research Guidance for IdustryWaiver of In Vivo Bioavailability and Bioequivalence Studies for Immediate-Release Solid Oral Dosage Forms Based on a Biopharmaceutics Claasification System Guidance for Industry pdf. 2000. 